\title{
In-vitro studies of ineffective erythropoiesis in rheumatoid arthritis
}

\author{
R. A. WILLIAMS, DIANA SAMSON, ${ }^{*} \mathrm{~J}$. TIKERPAE, * HELEN CROWNE, * \\ AND J.M. GUMPEL
}

From the Department of Rheumatology and *Section of Haematology, Northwick Park Hospital and Clinical Research Centre, Watford Road, Harrow, Middlesex HA1 3UJ

SUMMARY Ineffective erythropoiesis was assessed in a series of 32 patients with rheumatoid arthritis by means of a new in-vitro method which measures the release of haem from a labelled cohort of erythroblasts in culture. Haem release was significantly increased in patients with the anaemia of chronic disorders but was normal in those who were not anaemic or who had an iron-deficiency anaemia. In 2 patients with anaemia of chronic disorders haem release returned to normal after successful antirheumatic therapy. The increased ineffective erythropoiesis in patients with rheumatoid arthritis and anaemia of chronic disorders appeared to be unrelated to functional iron deficiency and was not attributable to a serum factor.

A moderate anaemia is common in patients with rheumatoid arthritis, and a number of factors are known to be involved in its production. ${ }^{1}$ One of the most important components is abnormal storage of iron by the reticuloendothelial system with a failure of release of iron to developing erythroblasts. ${ }^{23}$ Insufficient erythropoietin production ${ }^{4}$ and a small reduction in mean cell life ${ }^{6}$ are additional factors which may contribute to the anaemia. Ineffective erythropoiesis in the anaemia of rheumatoid arthritis was first described by Samson et al., ${ }^{7}$ who found a marked increase in a patient with active rheumatoid arthritis using an in-vivo method based on early labelled bilirubin production; this returned to normal levels after the patient had been successfully treated with gold and was no longer anaemic. ${ }^{8}$ This work was criticised on methodological grounds by Cavill and Ricketts, ${ }^{9}$ who had found no increase in ineffective erythropoiesis in 4 patients with rheumatoid arthritis using a computer-assisted ferrokinetic method. Subsequently Dinant and de Maat, ${ }^{6}$ also using the ferrokinetic method, reported increased ineffective erythropoiesis in 6 of 14 patients with the anaemia of rheumatoid arthritis, the mean level being $33 \%$ compared with a mean normal level of $21 \%$. They noted the similarity of their results in these patients with rheumatoid arthritis to those obtained by Ricketts $e t$

Accepted for publication 14 September 1981.

Correspondence to Dr D. Samson, Northwick Park Hospital, Watford Road, Harrow, Middlesex HA1 3UJ. $a l .{ }^{10}$ in a group of iron-deficient patients and suggested that reduced availability of iron might be the cause of the increased ineffective erythropoiesis in the anaemia of rheumatoid arthritis.

The present work was undertaken in order to study a larger group of patients with rheumatoid arthritis by a new simple in-vitro method of assessing ineffective erythropoiesis, including wherever possible repeat studies after successful antirheumatic therapy. In addition we wished to determine whether there was any relation between ineffective erythropoiesis and clinical or laboratory indices of disease activity, and to compare the results with those in patients with iron-deficiency anaemia and with anaemia due to other chronic disorders.

\section{Materials and methods}

\section{PATIENTS}

Patients gave informed consent to participation in this study, which had been approved by the Hospital Ethical Committee.

We report the results of studies in 32 patients with rheumatoid arthritis, none of whom had abnormal hepatic or renal function or any other systemic disorder known to cause anaemia. There were 23 females and 9 males of average age $57 \cdot 8$ years (range 18-73). All had either classical or definite disease according to the revised criteria of the American Rheumatism Association. ${ }^{11}$ We had previously studied 12 patients with rheumatoid arthritis and the 
anaemia of chronic disorders, two being studied on 2 separate occasions. As the incubation times in these preliminary studies were 72 hours we have not included data on these patients, but the results were all comparable to those with 96-hour incubations reported below.

The spectrum of disease activity ranged from active arthritis, anaemia, and systemic upset to less active joint disease without other system involvement. All patients were taking some form of nonsteroidal anti-inflammatory agent; levels of additional drug treatment were appropriate to disease activity, although no patient was taking cytotoxic drugs. At the time of bone marrow aspiration, a single observer (R.W.) assessed the patient's disease activity. This involved noting any features of systemic disease such as severe weight loss, palpable lymphadenopathy or splenomegaly, subcutaneous nodule formation, or vasculitis. Also noted were the duration of early morning stiffness, the grip strength, and an articular index based on that of Ritchie et al. ${ }^{12}$ Laboratory tests included a full blood count, erythrocyte sedimentation rate (ESR), serum proteins, and iron and iron binding capacity. Ferritin levels (Ramco kit method) were measured in 13 patients and C-reactive protein levels were measured in 14 patients. Radiological evidence of erosive joint disease was sought. On the basis of routine laboratory data the patients were subsequently divided into 3 groups (see 'Results' section below). Clinical and laboratory data in the 3 groups are shown in Tables 1 and 2. Three patients were studied on two separate occasions (see Table 3). Two patients (cases 1 and 2) were studied when anaemic and again after their anaemia had improved following successful antirheumatic therapy, and the third (case 3 ) was studied initially when only mildly anaemic $(\mathrm{Hb} 11.2 \mathrm{~g} / \mathrm{dl})$ and later when his general condition had deteriorated and his haemoglobin had fallen to $7 \cdot 9 \mathrm{~g} / \mathrm{dl}$.

Ten patients with the anaemia of chronic disorders associated with diseases other than rheumatoid arthritis were studied. They included 2 patients with giant cell arteritis, 3 patients with chronic renal failure and one patient with each of the following: carcinomatosis, osteomyelitis, infected varicose ulcers, polymyalgia rheumatica, and primary amyloidosis.

Table 1 Patients with rheumatoid arthritis: clinical features

\begin{tabular}{llll}
\hline & $\begin{array}{l}\text { Group 1: } \\
\text { anaemia of } \\
\text { chronic disorders } \\
n=22^{*}\end{array}$ & $\begin{array}{l}\text { Group 2: } \\
\text { nonanaemic }\end{array}$ & $\begin{array}{l}\text { Group 3: } \\
\text { iron-deficiency } \\
\text { anaemia } \\
n=4\end{array}$ \\
\hline Early morning stiffness (h) & $1 \cdot 7 \pm 1 \cdot 0$ & $0 \cdot 9 \pm 1 \cdot 3$ \\
Grip strength (mmHg) & $101 \pm 33$ & $122 \pm 61$ & $1 \cdot 0 \pm 1 \cdot 7$ \\
Articular index & $13 \cdot 8 \pm 8 \cdot 6$ & $9 \cdot 2 \pm 7 \cdot 5$ & $100 \pm 29$ \\
Disease duration (yr) & $4 \cdot 6 \pm 7 \cdot 1$ & $4 \cdot 1 \pm 3 \cdot 2$ & $9 \cdot 2 \pm 9 \cdot 6$ \\
Extra articular disease (other than anaemia) & 17 & 7 & $9 \cdot 6 \pm 9 \cdot 0$ \\
Joint erosions on $x$-ray & 15 & 2 & 3 \\
Treatment with gold & 3 & 0 & 0 \\
D-penicillamine & 2 & 1 \\
Prednisone & 5 & 0 \\
\hline
\end{tabular}

*Including one patient studied on 2 occasions.

+Including data relating to a subsequent study of 2 patients previously included in group 1 .

Table 2 Patients with rheumatoid arthritis: laboratory features. All data are mean $\pm 1 S D$

\begin{tabular}{|c|c|c|c|}
\hline & $\begin{array}{l}\text { Group } 1 \\
\text { anaemia of } \\
\text { chronic disorders } \\
n=22^{*}\end{array}$ & $\begin{array}{l}\begin{array}{l}\text { Group } 2 \\
\text { nonanaemic }\end{array} \\
n=9+\end{array}$ & $\begin{array}{l}\text { Group } 3 \\
\text { iron deficiency } \\
\text { anaemia } \\
n=4\end{array}$ \\
\hline Haemoglobin level (g/dl) & $9 \cdot 2 \pm 1 \cdot 7$ & $12 \cdot 3 \pm 1 \cdot 2$ & $8 \cdot 8 \pm 1 \cdot 7$ \\
\hline $\operatorname{MCV}(\mathrm{fl})$ & $78 \pm 5$ & $84 \pm 4$ & $70 \pm 5$ \\
\hline Platelet count $\times 10^{\circ} / 1$ & $465 \pm 129$ & $307 \pm 55$ & $385 \pm 191$ \\
\hline Erythrocyte sedimentation rate ( $\mathrm{mm}$ in $1 \mathrm{~h})$ & $97 \pm 38$ & $47 \pm 22$ & $52 \pm 27$ \\
\hline C-reactive protein level $(\mathrm{mg} / 100 \mathrm{ml})$ & $6 \cdot 3 \pm 5(n=7)$ & $0 \cdot 7 \pm 0 \cdot 2(n=5)$ & $2 \pm 0 \cdot 5(n=2)$ \\
\hline Serum ferritin levels $(\mathrm{mg} / \mathrm{l})$ & $42 \cdot 9 \pm 32(n=6)$ & $27 \cdot 1 \pm 22 \cdot 7(n=5)$ & $5 \cdot 8(n=2)$ \\
\hline Serum iron $(\mu \mathrm{mol} / \mathrm{l})$ & $4 \cdot 5 \pm 2 \cdot 4$ & $10 \pm 6 \cdot 6$ & $3 \cdot 5 \pm 1 \cdot 9$ \\
\hline Serum iron binding capacity $(\mu \mathrm{mol} / \mathrm{l})$ & $51 \cdot 6 \pm 9 \cdot 1$ & $57 \cdot 1 \pm 11 \cdot 4$ & $74 \cdot 2 \pm 5 \cdot 2$ \\
\hline Serum albumen $(g / 1)$ & $36 \cdot 6 \pm 4 \cdot 5$ & $42 \cdot 0 \pm 4 \cdot 2$ & $37 \cdot 2 \pm 4 \cdot 0$ \\
\hline Serum globulin $(g / l)$ & $37 \cdot 5 \pm 11 \cdot 5$ & $30 \cdot 6 \pm 5 \cdot 6$ & $30 \cdot 2 \pm 4 \cdot 9$ \\
\hline Positive rheumatoid factor & 13 & 3 & 3 \\
\hline Positive antinuclear factor & 4 & 0 & 2 \\
\hline
\end{tabular}

*Including one patient studied on 2 occasions.

+Including data relating to a subsequent study of 2 patients previously included in group 1. 
Table 3 Clinical and laboratory data and ${ }^{59} \mathrm{Fe}$ haem release in patients studied on 2 occasions

\begin{tabular}{|c|c|c|c|c|c|c|}
\hline \multirow[t]{2}{*}{ Patient study } & \multicolumn{2}{|l|}{ Case 1} & \multicolumn{2}{|l|}{ Case 2} & \multicolumn{2}{|l|}{ Case 3} \\
\hline & $a$ & $b$ & $a$ & $b$ & $a$ & $b$ \\
\hline $\begin{array}{l}\mathrm{Hb}(\mathrm{g} / \mathrm{dl}) \\
\mathrm{MCV}(\mathrm{fl}) \\
\text { ESR }(\mathrm{mm} \text { in } 1 \mathrm{~h}) \\
\text { Serum Fe/TIBC }(\mu \mathrm{mol} / \mathrm{l}) \\
\text { Morning stiffness }(\mathrm{h}) \\
\text { Grip strength }(\mathrm{mmHg}) \\
\text { Articular index } \\
\text { Drugs }\end{array}$ & $\begin{array}{l}7 \cdot 9 \\
78 \\
132 \\
3 / 36 \\
3 \\
55 \\
19 \\
\text { Prednisone }\end{array}$ & $\begin{array}{l}11 \cdot 4 \\
82 \\
71 \\
4 / 54 \\
3 \\
60 \\
8 \\
\text { Aspirin }\end{array}$ & $\begin{array}{l}7 \cdot 7 \\
79 \\
125 \\
3 / 54 \\
1 \\
80 \\
16 \\
\text { NSAID }\end{array}$ & $\begin{array}{l}12 \cdot 6 \\
80 \\
30 \\
8 / 66 \\
0 \\
150 \\
7 \\
\text { NSAID }\end{array}$ & $\begin{array}{l}11 \cdot 2 \\
87 \\
127 \\
2 / 51 \\
3 \\
80 \\
14 \\
\text { NSAID }\end{array}$ & $\begin{array}{l}7 \cdot 9 \\
85 \\
128 \\
3 / 51 \\
1 \cdot 5 \\
150 \\
11 \\
\text { NSAID }\end{array}$ \\
\hline${ }^{59} \mathrm{Fe}$ haem release $(\%)$ & $26 \cdot 8$ & $14 \cdot 8$ & $54 \cdot 3$ & $14 \cdot 9$ & $12 \cdot 4$ & $23 \cdot 2$ \\
\hline
\end{tabular}

NSAID = nonsteroidal anti-inflammatory drugs.

Eight patients with iron deficiency anaemia of varying aetiology were studied in addition to the 4 who also had rheumatoid arthritis. Haematological data in these patients and in 12 normal controls are shown in Table 4.

In this study haemoglobin levels of $13 \mathrm{~g} / \mathrm{dl}$ in males and $11 \mathrm{~g} / \mathrm{dl}$ in females were taken as the lower limit of normal.

\section{METHODS}

Full details of the method have been published elsewhere. ${ }^{13}$ Approximately $1 \mathrm{ml}$ of bone marrow is obtained by aspiration, and after washing the cells are incubated in $50 \%$ incubation medium (folate- and iron-free) and $50 \%$ autologous serum in the presence of transferrin-bound ${ }^{59} \mathrm{Fe}$ so that haem synthesised by erythroblasts is labelled. After 24 hours the cells are washed to remove free ${ }^{59} \mathrm{Fe}$ and reincubated for a further 72 hours, giving a total incubation time of 96 hours. During this time the death of cells results in the release of haem into the supernatant, and this is measured by extracting and counting the haem from the cells and from the supernatant (Fig. 1). The percentage of total labelled haem counts appearing in the supernatant is termed the percentage haem

Table 4 Haematological data in control subjects and patients without rheumatoid arthritis

\begin{tabular}{|c|c|c|c|}
\hline & $\begin{array}{l}\text { Control } \\
\text { subjects* }\end{array}$ & $\begin{array}{l}\text { Anaemia of } \\
\text { chronic } \\
\text { disorders } \\
\text { other than } \\
R A \\
n=10\end{array}$ & $\begin{array}{l}\begin{array}{l}\text { Iron- } \\
\text { deficiency } \\
\text { anaemia }\end{array} \\
n=8\end{array}$ \\
\hline $\begin{array}{l}\text { Haemoglobin level } \\
(\mathrm{g} / \mathrm{dl}) \\
\operatorname{MCV}(\mathrm{fl})\end{array}$ & $\begin{array}{l}13 \cdot 7 \pm 1 \cdot 7 \\
87 \pm 5\end{array}$ & $\begin{array}{l}9 \cdot 3 \pm 2 \cdot 1 \\
85 \pm 9\end{array}$ & $\begin{array}{l}6 \cdot 6 \pm 1 \cdot 2 \\
70 \pm 7\end{array}$ \\
\hline $\begin{array}{l}\text { Erythrocyte sedimenta- } \\
\quad \text { tion rate }(\mathrm{mm} \text { in } 1 \mathrm{~h}) \\
\text { Serum iron }(\mu \mathrm{mol} / \mathrm{l}) \\
\text { Serum iron binding capacity } \\
\quad(\mu \mathrm{mol} / \mathrm{l})\end{array}$ & $\begin{array}{l}- \\
-\end{array}$ & $\begin{array}{l}66 \pm 41 \\
7 \cdot 0 \pm 3 \cdot 8 \\
50 \cdot 6 \pm 8 \cdot 0\end{array}$ & $\begin{array}{l}27 \pm 20 \\
4 \cdot 3 \pm 2 \cdot 5 \\
83 \cdot 4 \pm 15 \cdot 6\end{array}$ \\
\hline
\end{tabular}

*Data from Samson et al. ${ }^{13}$

release and is an index of ineffective erythropoiesis. Although haem release cannot be directly equated with ineffective erythropoiesis, comparison with the results obtained in normal controls and patients with diseases such as megaloblastic anaemia ${ }^{13}$ enables some degree of quantitative assessment to be made.

In an experiment to determine the effect of serum from patients with the anaemia of rheumatoid arthritis on normal marrow, material from a normal volunteer was set up by using 6 different sera: autologous serum, sera from 3 patients with anaemia of

1.

2.

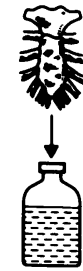

3.

4.<smiles></smiles>

Wash

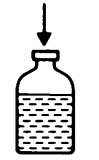

Re-incubate for a further 72 hours (total 96 hours)

Suspend in medium containing autologous serum and incubate with $59 \mathrm{Fe}$ transferrin for 24 hours at $37^{\circ} \mathrm{C}$.

5.

6.

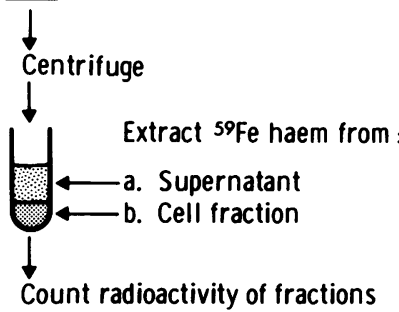

$$
\% 59 \mathrm{Fe} \text { haem release }=\frac{\text { Counts in supernatant } \times 100}{\text { Counts in supernatant plus }}
$$

Fig. 1 Measurement of ${ }^{59} \mathrm{Fe}$ haem release. 
rheumatoid arthritis who had shown increased haem release in culture of their own marrow, and sera from 2 nonanaemic patients with rheumatoid arthritis who had not shown increased haem release. The test sera had been stored at $-20^{\circ} \mathrm{C}$ for up to 6 months.

\section{Results}

On the basis of routine laboratory data (Table 2) the patients with rheumatoid arthritis could be divided into 3 groups. The first group of 21 patients had the classical anaemia of chronic disorders, with normochromic normocytic or microcytic anaemia associated with a low serum iron and normal or low iron binding capacity. Marrow iron stores were present in all cases; minor dyserythropoietic features were frequently observed, but no sideroblastic changes were seen. Active joint disease was more evident in these patients in terms of symptoms, signs, and laboratory indicators, and other system involvement was more common. C-reactive protein (CRP) and ferritin levels were generally higher in this group. The second group was of 9 patients who were not anaemic and whose arthritis was less severe or in at least partial remission. Lastly, 4 patients were iron-deficient with hypochromic microcytic anaemia, very low serum iron, high serum iron binding capacity, and absent marrow iron stores. While the haemoglobin levels of these patients were comparable to those with the classical anaemia of chronic disorders, in other respects they resembled the nonanaemic group.

\section{HAEM RELEASE}

Increased haem release (Table 5) was found only in group 1 patients (those with the anaemia of chronic disorders), and was present in 11 of 22 patient studies (Fig. 2). The mean haem release in these 22 patients was $24 \cdot 1 \%$, almost twice the mean haem release

Table $5{ }^{59} \mathrm{Fe}$ haem release after 96 hours' incubation

\begin{tabular}{|c|c|c|c|c|}
\hline & $n$ & $\begin{array}{l}{ }^{59} \mathrm{Fe} \text { haem } \\
\text { release }(\%) \\
\text { mean } \pm \text { I SD }\end{array}$ & t value; & p value* \\
\hline $\begin{array}{l}\text { Control } \dagger \\
\text { Rheumatoid arthritis } \\
\text { Group 1: } \\
\text { anaemia of } \\
\text { chronic disorders } \\
\text { Group 2: } \\
\text { nonanaemic } \\
\text { Group 3: } \\
\text { iron-deficiency } \\
\text { anaemia } \\
\text { Anaemia of chronic } \\
\text { disorders other } \\
\text { than RA } \\
\text { Iron-deficiency } \\
\text { anaemia }\end{array}$ & $\begin{array}{r}10 \\
8\end{array}$ & $\begin{array}{l}24 \cdot 1 \pm 12 \cdot 5 \\
12 \cdot 4 \pm 1 \cdot 7\end{array}$ & $\begin{array}{l}2 \cdot 78 \\
0 \cdot 89\end{array}$ & $\begin{array}{l}<0.005 \\
\text { NS }\end{array}$ \\
\hline
\end{tabular}

$*\left(n_{1}+n_{2}\right)$ DF. NS $=$ not significant at $p=0.01$ level.

+Samson et al. ${ }^{13}$.

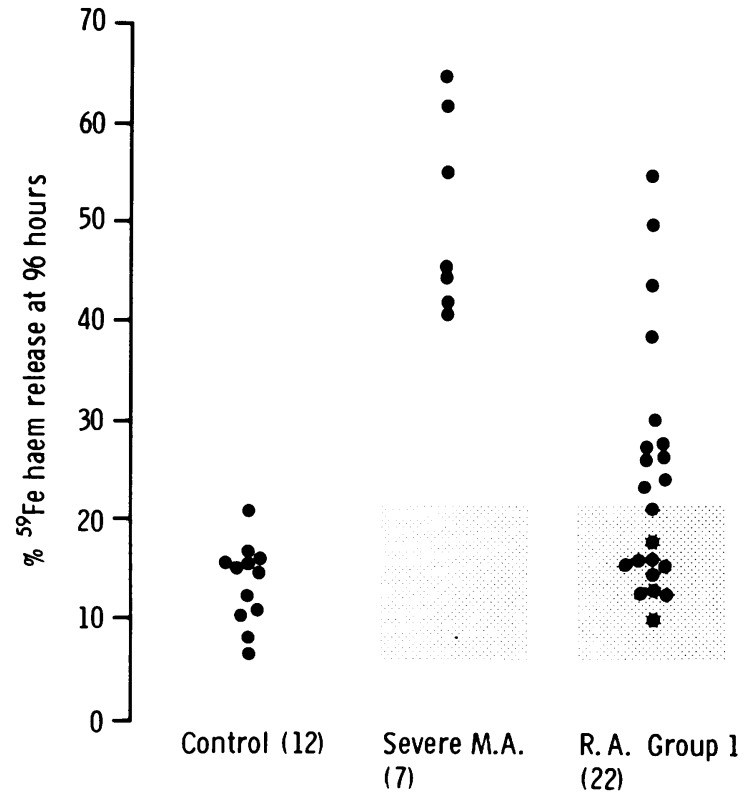

Fig. $2{ }^{59} \mathrm{Fe}$ haem release at 96 hours in $R A$ group 1 (anaemia of chronic disorders) compared with control subjects and patients with severe megaloblastic anaemia (MA) (Samson et al. ${ }^{13}$ ). The shaded area is the observed normal range.

found in the control subjects, and the difference reached statistical significance $(p<0 \cdot 005)$. The mean levels of haem release in the other groups of patients with RA (nonanaemic and iron-deficient) were similar to that found in control subjects (Table 5) and in no individual was an increased level of haem release found (Fig. 3). Similarly haem release was normal in patients with anaemia of chronic disorders due to other causes and in those with simple iron deficiency.

In 2 patients (cases 1 and 2) with initially high levels of haem release, a subsequent investigation 6 months later after relative response to nonsteroidal anti-inflammatory drugs showed that haem release had returned to normal levels (Fig. 3). One patient (case 3), who had marked systemic features such as weight loss present at both investigations, produced an elevated level of haem release some months after a normal level, and had deteriorated markedly in some but not all indices of disease activity in the interim. Details of laboratory indices for these 3 patients are shown in Table 3.

In terms of specific features of active disease, we could find no statistical correlations between duration of morning stiffness, articular index, or ESR levels and haem release. However, when the results for group 1 (RA with anaemia of chronic disorders) and group 2 (nonanaemic RA) were combined 

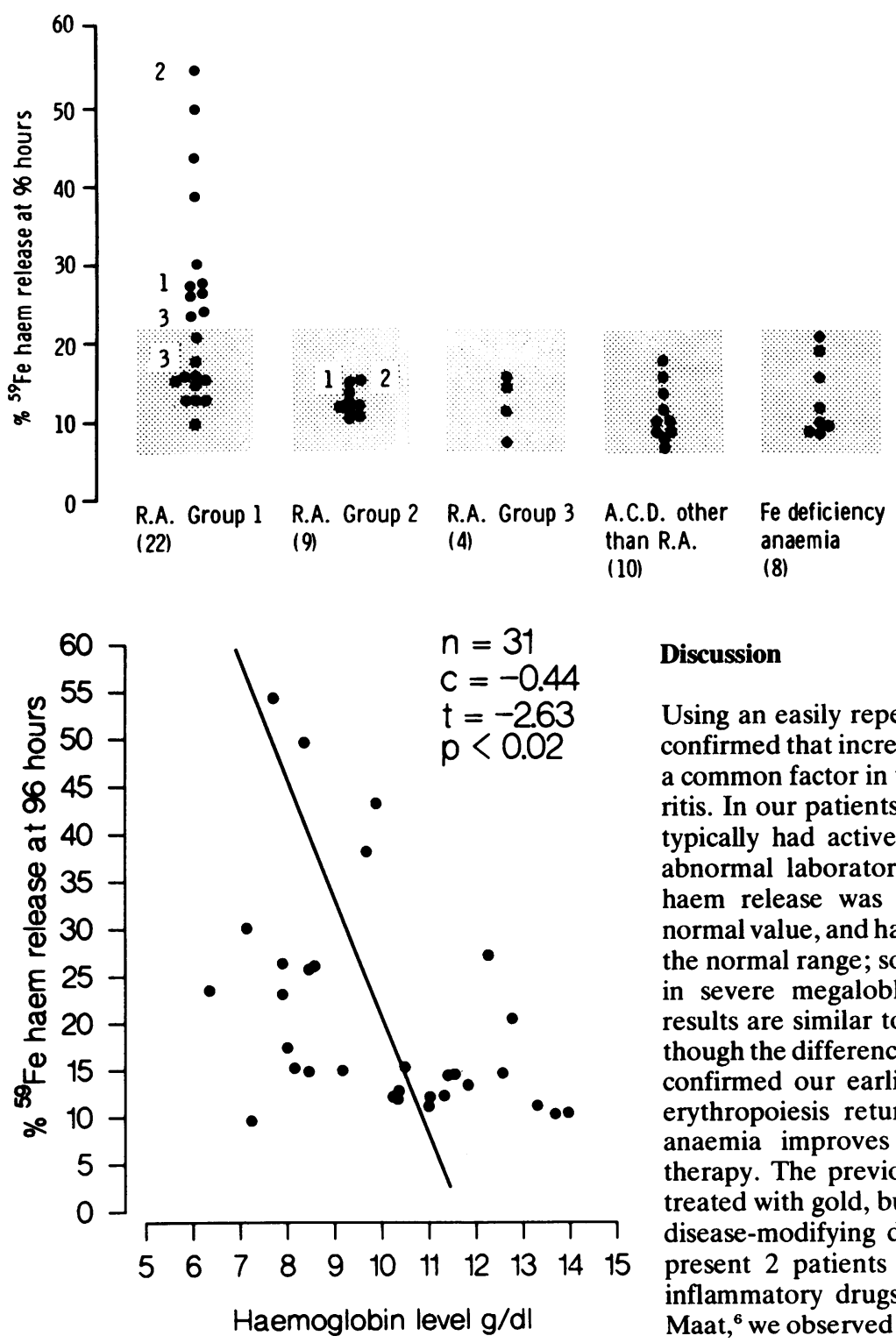

Fig. 4 Correlation of ${ }^{59} \mathrm{Fe}$ haem release with haemoglobin level in patients with rheumatoid arthritis excluding those with iron-deficiency anaemia.

(Fig. 4), we found a statistically significant inverse correlation between haem release and haemoglobin levels $(\mathrm{p}<0.02)$.

SERUM EXPERIMENTS

As shown in Table 6, serum from patients with or without ineffective erythropoiesis did not appear to have any effect on a normal bone marrow.

\section{Discussion} arthritis on normal marrow
Fig. $3{ }^{59} \mathrm{Fe}$ haem release at 96 hours in the different patient groups. The patients with rheumatoid arthritis studied on 2 occasions are indicated by their case numbers. The shaded area is the observed normal range. $R A=$ rheumatoid arthritis, $A C D=$ anaemia of chronic disorders.

Using an easily repeatable in-vitro method we have confirmed that increased ineffective erythropoiesis is a common factor in the anaemia of rheumatoid arthritis. In our patients with this type of anaemia, who typically had active joint symptoms and signs and abnormal laboratory findings, the mean value for haem release was approximately twice the mean normal value, and half the patients had values outside the normal range; some had values in the range seen in severe megaloblastic anaemia (Fig. 2). These results are similar to those of Dinant and de Maat, ${ }^{6}$ though the difference from normal is greater. We also confirmed our earlier observation ${ }^{8}$ that ineffective erythropoiesis returns to normal levels when the anaemia improves with successful antirheumatic therapy. The previously reported patient had been treated with gold, but this was not a specific effect of disease-modifying drugs, as it was also seen in the present 2 patients treated with nonsteroidal antiinflammatory drugs. In contrast to Dinant and de Maat, ${ }^{6}$ we observed a significant correlation between

Table 6 Effect of serum from patients with rheumatoid

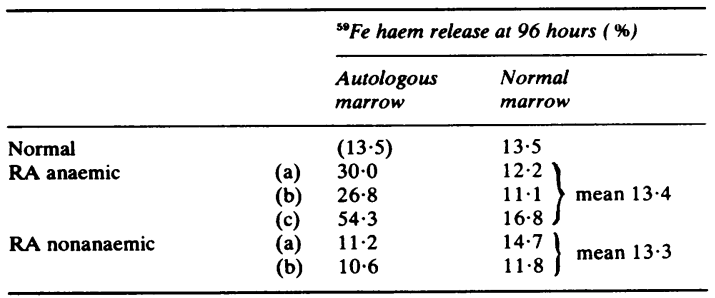


ineffective erythropoiesis and haemoglobin. However, a number of patients showed normal levels of haem release despite having anaemia and active joint disease, consistent with the multifactorial nature of the anaemia.

The relationship of haem release to other indicators of joint disease activity also seems complicated in that we found no correlation with individual indices in spite of definite changes with overall clinical condition. At one stage in the study it appeared that there were significant correlations between haem release and ESR, globulin levels, and platelet counts, but these were lost as the groups became larger. Other factors such as the duration of disease or the type of drug treatment played no obvious part in increasing haem release in our patients.

The cause of the increased ineffective erythropoiesis in the anaemia of rheumatoid arthritis remains unclear. Dinant and de Maat ${ }^{6}$ suggested that it might be related to functional iron deficiency. Previous work ${ }^{74}$ has shown that ineffective erythropoiesis is moderately increased in some cases of iron-deficiency anaemia, although this is a minor factor in the production of the anaemia. ${ }^{7}$ In the patients with iron deficiency studied by Cavill et al. ${ }^{14}$ approximately half had elevated values for ineffective erythropoiesis, but in the present group of patients none had increased levels of haem release. This may reflect a difference in the severity of the iron deficiency between the 2 series or may be due to methodological factors. Nevertheless, the present method shows there is a clear difference between the iron-deficient patients and those with the anaemia of rheumatoid arthritis, suggesting that functional iron-deficiency is unlikely to contribute significantly to the increased ineffective erythropoiesis in the anaemia of rheumatoid arthritis.

If functional iron deficiency were a major component in causing increasing ineffective erythropoiesis, equal increases would be expected in patients with anaemia associated with other chronic disorders in which there is also inadequate iron supply. Although relatively few patients in this group were studied and their diseases were heterogeneous, the normal values for haem release support the view that the increased erythropoiesis in rheumatoid arthritis is unrelated to altered iron metabolism. Thus there appears to be a particular factor in active rheumatoid arthritis which causes increased ineffective erythropoiesis and which responds to an improvement in the arthritis with antirheumatic therapy. There may be an immune-mediated mechanism for the increased cell death, and, although we were unable to demonstrate a cytotoxic effect of rheumatoid serum, cell-mediated cytotoxicity remains a possibility.

We thank our colleagues for allowing us to study patients under their care. D.S. and J.M.G. thank the Arthritis and Rheumatism Council for providing financial support for technical assistance.

\section{References}

${ }^{1}$ Mowat A G. Hematologic abnormalities in rheumatoid arthritis. Semin Arthritis Rheum 1971; 1: 195-219.

2 Beamish M R, Davies A G, Eakins J D, Jacobs A, Trevett D. The measurement of reticulo-endothelial iron release using iron dextran. Br J Haematol 1971; 21: 617-22.

${ }^{3}$ Bennett $\mathbf{R}$ M, Holt P J L, Lewis S M. Role of the reticuloendothelial system in the anaemia of rheumatoid arthritis. Ann Rheum Dis 1974; 33: 147-52.

4 Ward H P, Gordon B, Pickett J C. Serum levels of erythropoietin in rheumatoid arthritis. J Lab Clin Med 1969; 74: 93-7.

5 Wallner S F, Kurnick J E, Vautrin $R$ M, White $J$ M, Chapman R G, Ward H P. Levels of erythropoietin in patients with the anaemias of chronic diseases and liver failure. $\mathrm{Am} \mathrm{J}$ Haematol 1977; 3: 37-55.

- Dinant H J, de Maat C E M. Erythropoiesis and mean cell lifespan in normal subjects and in patients with the anaemia of active rheumatoid arthritis. Br J Haematol 1978; 39: 437-44.

7 Samson D, Halliday D, Nicholson D C, Chanarin I. Quantitation of ineffective erythropoiesis from the incorporation $\left[{ }^{15} \mathrm{~N}\right]$ deltaaminolaevulinic acid and $\left[{ }^{15} \mathrm{~N}\right]$ glycine into early labelled bilirubin. II. Anaemic patients. Br J Haematol 1976; 34: 45-53.

- Samson D, Halliday D, Gumpel J M. Role of ineffective erythropoiesis in the anaemia of rheumatoid arthritis. Ann Rheum Dis 1977; 36: 181-5.

- Cavill I, Ricketts C. Ann Rheum Dis Role of ineffective erythropoiesis in anaemia of RA. 1977; 36: 592.

10 Ricketts D, Jacobs A, Cavill I. Ferrokinetics and erythropoiesis in man: the measurement of effective erythropoiesis, ineffective erythropoiesis and red cell lifespan using ${ }^{59} \mathrm{Fe} . \mathrm{Br} J$ Haematol 1975; 31: 65-75.

11 Ropes M W. Diagnostic criteria for rheumatoid arthritis. 1958 Revision. Ann Rheum Dis 1959; 18: 49-51.

12 Ritchie D M, Boyle J A, Mclnnes J M, et al. Clinical studies with an articular index for the assessment of joint tenderness in patients with rheumatoid arthritis. $Q J$ Med 1968; 37: 393-406.

13 Samson D, Tikerpae J, Crowne H. A simple in vitro method for the assessment of ineffective erythropoiesis. Blood 1981; 58: 782-7.

14 Cavill I, Ricketts C, Napier J A F, Jacobs A. Ferrokinetics and erythropoiesis in man: red cell production and destruction in normal and anaemic subjects. Br J Haematol 1977; 35: 33-40. 